\title{
An Ethnographic Study on Indigenous Shea Butter Extraction and the Use of the By-Products
}

\author{
Anna Mwinbuabu Naah ${ }^{1}$, Peter Bilatam Mayeem ${ }^{2}$, Valentina Osei-Himah ${ }^{3}$ \\ ${ }^{1,2}$ Offinso College of Education, Ghana \\ ${ }^{3}$ Atebubu College of Education, Ghana \\ Corresponding Author: Valentina Osei-Himah
}

\section{ABSTRACT}

Indigenous knowledge practices are locally based systems of knowledge, uniquely associated with a group of people in a cultural setting. These practices, which have evolved over time generally, denote a broad and collective consciousness of the people, including their nature, habitats and interpersonal relationships. Indeed, this knowledge concept sustains the lives of the people. They depend on it to navigate as well as assail their everyday experiences, including in particular those that serve as serious threats to their livelihood. The processes involved in Shea butter extraction exemplify a shared body of indigenous knowledge system noted with the people of Northern Ghana. Unfortunately, many people are oblivious of the existence of such Shea butter industry. Consequently, there is no way they can have knowledge of the by-products that emerge from the industry let alone appreciate their uses. This study aimed to address the prevailing ignorance and especially fill the extant knowledge gap concerning the by products of local Shea butter extraction and their indigenous uses. An ethnographic method was adopted whereby 5 women, engaged in the production of Shea-butter, were purposively sampled. Data emerged from 2 primary sources, namely participatory observation and interview. Cross-cutting issues were delineated from the captured data. These were transcribed, documented and content analysed along the cross-cutting issues. The findings revealed the processes involved in Shea butter extraction as parboiling, drying, grating, frying, pounding, milling and stirring. Besides, the by-products of the extraction process were identified as 'kabala', used for plastering walls and floor
\end{abstract}

making, and then 'kaamuni', employed in the generation of heat, lighting and fire making. Scientific concepts suggested to account for the manner the by-products are used included cohesion, adhesion, friction and bonding. It was concluded that further research needed to be conducted to explain and confirm these suggested scientific concepts.

Key Words: Indigenous knowledge, shea butter, shea nuts,

\section{INTRODUCTION}

Indigenous knowledge, with its own beliefs and practices is culturally diverse and orally transmitted from generation to generation. Indigenous knowledge is used today in many parts of the world, particularly in rural settlements, for the dayto-day activities of people. This type of knowledge incorporates technologies which the people have depended on for adaptation to their environment as well as their survival as a whole. As observed by Lutomia and Bello-Bravo (2017), notwithstanding the fact that indigenous people live within this knowledge concept that governs their everyday experiences, including threats to livelihood encountered but surmounted through dependence on this knowledge, not much has been researched into this knowledge system to both preserve and disseminate it to others that could benefit from it.

The Shea tree is a quintessence of wildlife's bounty fauna in the harsh and dry terrain of sub-Saharan Africa. It is 

products.

particularly known to flourish well in the northern part of Ghana. The tree has a high commercial value especially in the confectionary, cosmetic and pharmaceutical industries. The healing effect on the skin from the butter that is extracted from its nuts has been known and used for centuries by Africans. Lately, the rest of the world has begun to enjoy these benefits. But processing Shea nuts into butter could be cumbersome given the many stages it has to go through. Nature has however made the first of these stages - the gathering of the nuts - a very attractive activity. Rural women and children in particular engage in Shea nut picking not only with the view to processing them into butter but also because of the tasty nature of the fruits the nuts are embedded. Thus, as observed by Quainoo et al (2020) when the season comes the people engage in Shea nut gathering and processing as their main source of livelihood. Apart from picking of the fruits the other stages of processing butter include; washing of the fruits, de-pupping, drying, seed selection, seed cracking, roasting of kernels, milling of kernels, boiling of ground kernels, filtering, solidifying and packaging.

As the main product from the Shea tree, Shea butter is rich in fats and fatty acids. This explains the high demand for it in America, Canada and Europe among others - a development that has made the Shea tree an important cash crop. Currently, Shea butter is among the top ten export commodities in Ghana and the most important export commodity in Burkina Faso after gold, cotton and livestock (Nde et $a l, 2016)$. Aside its being a cash crop, there are other relevant uses of the Shea. The latex from the Shea tree is mixed with palm oil and used as glue for minor repairs (Orwa et al, 2009). Moreover, its flowers can be fried as fritters and consumed. The sweet pulp of the Shea fruit has an important nutritional value for the native people and animals of sub-Saharan African. According to Gezahegn et al (2016) Shea nuts are consumed raw or slightly roasted. The butter from the nuts is sold in the local market. It has a good keeping quality if properly wrapped, to be used in cooking and the waxy part of the butter is suitable for candle making.

Given the myriad benefits from the butter derivative of the Shea tree, it is quite deserving of an important place in the field of research. Lutomia \& Bello-Bravo (2017), Karambiri et al (2016), Nde et al (2016) and Quainoo et al (2020) are unanimous with the view that though there has been some research in the area most have focused on the varieties, health benefits, nutritional values, the effect of Shea fruit sugar content on its butter quality as well as its economic importance.

Thus, there appears to be scanty research into the by-product of the Shea nuts after the extraction of Shea butter. A knowledge gap exists as to what these by products are and what indigenous people use them for. This study some indigenous knowledge systems into the extraction of butter from Shea nuts and the by-products thereof as well as the scientific processes involved have been explored with the view to contribute towards filling this gap. Thus an effort has been made to answer the following research questions:

i. How is the local extraction process of Shea butter like?

ii. How useful are the by-products of local Shea butter extraction?

iii. What scientific concepts account for the ways the by-products of local Shea butter extraction are used?

\section{METHOD}

The study was conducted in Takpo, a village with a population of about 3,000 inhabitants, in the Nadowli-Kaleo District of the Upper West Region of Ghana. Takpo was selected because not only are the people basically peasant farmers but also because of their long historical association with Shea butter processing, which indeed has been part of their socio-cultural and economic heritage. The community is considered to atypically have a broad and dependable 

products.

local knowledge about Shea-butter processing right from the raw Shea nuts.

The target population for the study was exclusively and purposively women. The accessible population in the community engaged in the production of Shea-butter was also women. A small sample of five women was used. Data for the study was obtained from primary sources using participatory observation and interview. Data obtained from observation were documented and those from interviews transcribed and grouped into themes. To ensure reliability of the data collected, a Social Science degree holder was purposefully selected and trained in participatory observation and interviewing skills to assist in independently noting down her own observations.

The women were informed of the purpose and duration of the research and their consent and that of their families sought. The women were aged between 25 and 35. The youngest and oldest of them had three and five children respectively. None of them had any formal education.

Working alongside my assistant, I employed unstructured focus group interviews to interact with the women. The interviews served as one means to have indepth knowledge and life experiences of the women. The interviews were so managed in accordance with the Cohen et al (2018) to assure an enabling environment for free expression of thought and views by the participants. The interview sections were managed through casual conversation in Dagaare (the local language of the community) with the women during their free time when they met to relax under a notable shady tree within the community. Both I and my assistant asked questions which were within the context and purpose of the study. Where responses elicited follow-up questions, we did not hesitate to ask them.

Since we acted as participant observers, we involved ourselves in most of the group's activities. For instance, we went out from our homes at dawn to meet at a junction and proceed to the bush together on to pick the Shea fruits. Going from one woman's home to the other we also participated in how the Shea nuts were processed into butter. At first hand, I therefore saw how the by-products were obtained.

Apart from the second opinion I sought to get from my trained assistant, the reliability of the data was further reinforced by transcribing the interview sessions and going back to read what the women had said to them. All information and data gathered were put together and cross-cutting issues were delineated. These were subsequently transcribed and documented and the content analysed thematically in terms of the crosscutting issues. These were put together and a composite summary made.

\section{RESULTS AND DISCUSSION}

The outcome or results of the study are as reported and discussed in the following which comes under three themes, to wit the Shea butter extraction process, the Shea butter extraction by-products and the local uses of the by-products and the supporting scientific concepts.

\section{The Shea butter Extraction Process}

The data were collected within the months of April, through to June. This was so because picking of Shea fruits starts from late April even though most fruits get matured and ripped in May.

\section{Gathering, de-Pulping, de-Shelling and Milling}

It was established that Shea fruits are only picked when they are matured since immature ones cannot be processed into any good butter. It was also observed that the fleshy edible fruits (pulp) were scrapped off to expose the nuts which were then parboiled. Eating of the fleshy fruit by as many people as possible was encouraged since that exposed the hard nuts. It was also observed that after boiling, the nuts were spread out in the open sun to dry for days. Complete drying, as explained is necessary to avoid producing bitter butter. The dried 

products.

Shea nuts were later cracked to remove the nuts from the shells. The nuts were then crushed or grated into smaller pieces and dry-fried in large empty aluminium cooking pots. Following this the fried grated nuts were pounded into a rough watery paste. This paste was further subjected to milling on either a grinding stone or by means of a grinding mill. It was noticed that manual milling on a stone went along dirges that praise-sing ancestral and family achievements. It was explained that the songs kind of assuaged the human effort that went into the activity - kind of turning a difficult task into a pleasant experience.

\section{Stirring, Mixing, Scooping, Boiling and Cooling}

With the paste now very smooth and collected into a big pot, I observed that it was stirred with a large locally made wooden spatula. This went on for up to some 30 minutes when light layers of fat began to show on the surface. Stirring was done in a comfortable sitting position and according to the women it actually forms part of the next step that is energy consuming. In effect it reduces the time for this next step. This next step involved adding a reasonable amount of warm water to the paste, stir awhile again with the spatula and, with such great energy and in a bent posture 'beat' or vigorously stir it rhythmically with an accompanying folk song using both hands. This can take up to some 20 minutes before a thick mass of suspended fat gathers. It was thus explained that but for the spatula stirring that preceded the hand beating process in that bent posture alone would last about an hour. At this point it was observed some cold water was added to make the thick mass of fat float to facilitate scooping it off. When scooped off the mass of fat was transferred to an aluminium pot on fire and hard heated for it to melt and also vaporize any traces of water.

The now boiling oil was on the fire for up to an hour to remove any odour associated with the rawness of the original
Shea nuts. Eventually, the oil was taken off the fire and allowed to cool. Once the temperature came down reasonably, it was gently decanted into a clean pot and kept away to cool overnight. The sediment at the very bottom after the decantation was poured into the inclined inner corner of a local straw basket. This served as a sieve through which the oily part of the sediment filtered and received into a receptacle placed below it. By the next morning, it was observed that both the decanted and filtered oils had solidified into a thick and light mast of white Shea butter respectively.

\section{The Shea Butter Extraction By-Products}

The study identified two essential by-products from the Shea-butter extraction process. In the Dagaare Language these are called kabala and kaamuni. Kabala, the first by-product is the chocolate-brown semicolloidal residue left after scooping off of the floating thick mass of fat. Kaamuni on the other hand refers to the residue left in the local straw basket after filtering/straining the sediment lodged at the very bottom following the decantation process described above.

\section{Uses of the by-products and the supporting scientific concepts}

The research established that Kabala is normally regarded as a waste by-product and therefore often discarded. It however has a few scientific applications including the following that some of the people are wont to take advantage of:

\section{Kabala: Check against soil erosion and scientific underpinnings}

Even when kabala is to be discarded as waste, there are those who would rather splash it out on land areas that are erosion prone. This is because with the massive dispersed fatty globules of butter suspended throughout this liquid it easily forms a waterproof-like coating on the land surface.

Having thought through this, the researcher suggests the following plausible explanations to the observed phenomenon. 

products.

Firstly it is reasonable to suggest that the fatty (oily) component of the kabala significantly reduces the frictional force on the land surface. This causes running rain water that would otherwise carry off particles of soil with it to simply glide or roll over the land without any degradation effect. Secondly it is thought that the inability of the rain water to penetrate the kabala-coated land is because of the reduced adhesive forces between the water molecules and particles of the land surface. This gives rise to a situation where the stronger cohesive forces between the water molecules subdue the weakened adhesive forces. The water molecules thus hold unto each other into a convex shape that enables them to roll on the carpet formed by the kabala. Besides, weakened adhesion between the water and soil particles means weakened capillarity that otherwise would have enabled the water to seep through the soil to cause damage.

\section{Kabala: Material for floor making:}

Another use of kabala that was observed in the study is its application in the indigenous building industry where it is combined with some aggregations. This particularly relates to floor-making and wall-plastering of traditional dwelling places. It was explained that for the byproduct to be used this way it is kept away in open pots for some time to 'season'. This means allowing some amount of its aqueous content to evaporate and make it little more viscous. When used for floor-making it is first mixed with fresh naabini (cow dung) and vuolung (an extremely slimy stuff mashed out of okra stocks). This mixture is in no defined proportions. The narrative indicated that, the evening before project execution day, the kabala-naabini-vuolung mixture is further mixed with zigree (coarse laterite dug out from the earth). The ratio of mixture of the kabala-naabini-vuolung mixture to zigree is about 1:5, using size 34 aluminium bucket as the unit of measure. The quantities used depend on the floor area concerned. The mixing process it was disclosed is done by strong young men using hoes and shovels. Once thorough mixing is over the entire mass is neatly packed and shaped into a big mound and left over night to 'mature'.

It was observed that apart from mixing and spreading out the zigree where men are involved, all other project processes are women business. Thus, the project owner is normally a woman. It is she who is the lead actor, with collaborative support coming from neighbours that she has informed, clear days ahead to come help. As the lead actor she rises up early morning on the project D-day and ensures the floor is worked on and neatly swept and readied. She next heavily sprinkles the entire floor with water and calls on the young men to evenly spread out the mixture to cover the entire floor space. Local brooms are used to further level up the spread and also to remove lumps.

Following this, all is set for the beating or compacting of the floor. This is when all hands come on deck with the women falling into position and hitting the floor hard with improvised wooden rammer compactors known in the local language as sampama (sampani for singular). Graphically, it is exciting to watch them line up side by side across the breadth of the floor and in a bending-and-rising posture and a steady backwards motion beat the floor in unison amidst sweet and rhythmic folksongs. This exciting scene would continue until they cover the entire length of the floor. Interspersed with breathers, this action is repeated over and over for about four rounds. Before each round some slimy water (water with vuolung) is sprinkled all over the floor. By the fourth round of rammer compacting the floor is well beaten and levelled into shape. The party then takes a much longer rest whilst the lead actor thinly applies mashed cow dung to cover the entire floor surface. The break lasts about an hour and a half during which some snacks and drink (pito) may be served. In the interim, the unfinished work also rests and goes through some hardening process to 

products.

facilitate the soon to follow-up final topdressing.

On resumption, the compacting process continues but with reduced intensity. In fact, smaller sampama are deployed at this stage to ensure a reduction on the ramming. Apart from the reduction in ramming intensity and the number of rounds, this second session of work is similar to the first. The rounds, which are reduced to two, conclude with a smooth and a well plastered floor comparable to one made of cement-sand mortar. A second thin layer of wet cow dung that has been mashed with a little wood ash is applied all over this new floor surface and now left to dry up. As it dries up in a day or two, the project owner takes steps to prevent people stepping on it.

\section{Kabala: Material for wall plastering}

It was observed from the study that the plastering of walls, with kabala as a component material, proceeds differently from the process used for floor making. While zigree (granite) is used as described above for floor making, a special type of soft soil, bobolaa (silt soil) is used in the case of wall plastering. The common factor between the two processes is kabala, which serves as a major 'bonding' component material used for both processes.

An impression from the study suggests zigree to be more abundant in the earth crust and can more easily be located and dug out than bobolaa (the local name for this intermediate loamy-clayey soil). Bobolaa is indeed a special type of top soil (silt) found in limited locations in the community. As top soil it is easy to dig out. Thus when a sufficient quantity of it is dug out, it is conveyed home and heaped in one place, much like zigree is done. Working with little portions at a time the bobolaa is sieved to remove particles of grass and root hairs. It is then mixed with water and kabala (in no determined ratio) using a small hoe. Mixing is done until it achieves a consistency similar to mortar (cement-sand mixture). Indeed, from the Researcher's perspective, there is very little to choose between mortar and mixed bobolaa in terms of physical appearance.

From what was observed an estimated wall area that would take the mixed bobolaa is normally marked out and sprinkled with water. An interval of time is allowed for the wall to absorb this water. Using pieces of broken calabashes as improvised trowels the mixed bobolaa is applied to the wall, in like manner that masons apply mortar to a wall that is to be plastered. When the entire estimated portion of wall is covered, the back of the broken pieces of calabash are used to dress it until a smooth surface results. The process is akin to working with an actual trowel except that the dressing is repeated over and over as the wall dries up. This is to ensure firm bonding. Using a piecemeal approach plastering is continued from one estimated wall area to another until the entire wall is done.

Complete drying up of the wall takes about a week. It was explained that since local homes are not conventionally painted, smearing the wall with mashed naabini (cow dung) comes in as a substitute. This protects the wall from chipping off easily. Generally, the naabini is applied to the inner walls. It is a simple process that uses a small smooth broom (a substitute for brush) to smear the naabini on the wall surface and left to dry. Even as the same could be done to outer wall indigenous people generally prefer splashing zunbeng on outer walls. As observed, zunbeng is a solution obtained by soaking empty pods of dawdaw fruits (left after removing the yellow pulp) in water for days. Normally the soaking continues until the resultant solution begins to exude an offensive odour. Naabini protects the wall but zunbeng protects it even better. Indeed, the protective power of zunbeng is so strong that it is often applied to even un-plastered walls and keep them erect and unaffected by rain for years. 

products.

Use of kabala for wall and floor making: Scientific underpinnings

In both floor making and wall plastering kabala, appears to serve as a bonding agent. The process by which it is able to do this is not known until properly investigated in future enquiries. For now it is suggested that the bonding from the components is a result of mechanical interlocking provided by epitaxic growth of the zigree or bobolaa hydration products on the other components. It could also result from chemical reactions between components of the mixture pastes. Kabala, it is thought serves to catalyse these reactions. Indeed, it was observed that walls or floors made without the addition of kabala as component resulted weakened durability of these walls and floors.

\section{Kaamuni: Material for setting of fires and lighting}

As a by-product of Shea butter, kaamuni is a combustible material. It was observed that Indigenous people find ready use for it in the setting of fires at home. Generally, charcoal and fire wood are used as sources of fire that generates heat for cooking. To facilitate the fire setting process, indigenous people are wont to add some amount of kaamuni to the charcoal or fire wood. The kaamuni sustains the initial fire from the matches until the charcoal or wood goes fully ablaze.

Kaamuni is also used as a source of fuel for a local lamp called 'fintena'. The fintena is a most valuable contrivance that provides light to homes at night, particularly in communities that lack electricity. Its use is similar to the use of a candle. It has a wick through which melted butter climbs up by capillary action to reach the fire and get burnt to produce light.

\section{CONCLUSION}

The Shea tree which bears Shea nuts grows naturally in the wild along the Northern regions of Ghana. Shea nut products are ideal for use as raw materials in cooking oil, margarine, cosmetics, soap, detergents and candles. The process of extraction Shea butter from the nuts is predominantly done by rural-based women using manual traditional methods. The Shea nuts business generates substantial income for the women to support their domestic needs. The women gather the Shea nuts which are taken through a number of processes to obtain Shea butter. Two main by-products, kabala and kaamuni, are obtained after the extraction of Shea butter. These by-products are very useful to the life of the people of the community. Kabala is mixed with zigree and used to make floors of local homes. It is also mixed with bobolaa for plastering walls. Various scientific concepts are involved in the use of the by-products. The full understanding of these concepts is beyond the scope of this study. It is suggested however that future research be conducted to come out with more detailed scientific underpinnings governing the use of the by-products as covered in this research.

\section{Acknowledgement: None}

\section{Conflict of Interest: None}

\section{Source of Funding: None}

\section{REFERENCES}

1. Gezahegn, Y. A., Emire, S. A., \& Asfaw, S. F. (2016). Optimization of Shea (Vitellaria paradoxa) butter quality using screw expeller extraction. Food Science \& Nutrition, 4(6): 840-847.

2. Karambiri, M., Elias, M., Vinceti, B., \& Grosse, A. (2016). Exploring local knowledge and preferences for Shea (Vitellaria paradoxa) ethnovarieties in Southwest Burkina Faso through a gender and ethnic lens. Forest, Trees and Livelihoods, 26(1), 13-28

3. Lutomia, A. N. \& Bello-Bravo, J. (2017). Communities of practice and indigenous knowledge: a case study of empowering women in processing shea butter using scientific animations. Retrieved from $25^{\text {th }}$ of May, 2021 from https://www.igiglobal.com/chapter/communities- ofpractice-and-indigenous-knowledge/167483 
Anna Mwinbuabu Naah et.al. An ethnographic study on indigenous shea butter extraction and the use of the byproducts.

4. Nde, D. B., Boldor, D., Astete, C., Muley, P., \& Xu, Z. (2016). Oil extraction from Sheanut (Vitellariaparadoxa Gaertn C.F.) kernels assisted by microwaves. Journal of Food Science and Technology. 53(3): $1424-1434$.

5. Orwa, C., Mutua, A., Kindt, R., Jamnadass, R. \& Anthony, S. (2009). Vitellaria paradoxa. agroforestree database: a tree reference and selection guide version. Retrieved from $4^{\text {th }}$ of September, 2021 from https://www.worldagroforestry.org/sites/tree dbs/treedatabases.asp
6. Quainoo, A. K., Jibrim, A. \& Chimsah, F. (2020). Effect of Shea fruit sugar content on Shea (vitellaria paradoxa l.) butter quality. UDS International Journal of Development [UDSIJD] 7(1) 256- 261

How to cite this article: Anna Mwinbuabu Naah, Peter Bilatam Mayeem, Valentina Osei-Himah. An ethnographic study on indigenous shea butter extraction and the use of the by-products. International Journal of Research and Review. 2021; 8(12): 695-702. DOI: https://doi.org/10. 52403/ijrr.20211284 